\title{
Labyrinthe
}

18 | 2004 (2)

La Recherche dans tous ses éclats

\section{Patrick Dandrey, Les Tréteaux de Saturne. Scènes de la mélancolie à l'époque baroque}

\section{Clotilde Thouret}

\section{Q OpenEdition}

\section{Journals}

Édition électronique

URL : https://journals.openedition.org/labyrinthe/206

DOI : 10.4000/labyrinthe.206

ISSN : 1950-6031

Éditeur

Hermann

\section{Édition imprimée}

Date de publication : 15 juillet 2004

Pagination : 25-28

Référence électronique

Clotilde Thouret, « Patrick Dandrey, Les Tréteaux de Saturne. Scènes de la mélancolie à l'époque baroque », Labyrinthe [En ligne], 18| 2004 (2), mis en ligne le 20 juin 2008, consulté le 21 septembre 2021. URL : http://journals.openedition.org/labyrinthe/206 ; DOI : https://doi.org/10.4000/labyrinthe 206 


\section{Les Tréteaux de Saturne. Scènes de la mélancolie à l'époque baroque de Patrick DANDREY*}

Clotilde Thouret

clotilde.thouret@worldonline.fr

Les Tréteaux de Saturne, qui inaugurent une nouvelle collection chez Klincksieck, se présentent comme «une contribution à l'histoire des représentations de cette ancienne mélancolie» : l'atrabile, ou bile noire, qui, dès l'Antiquité, constitue l'une des quatre humeurs se trouvant (avec le sang, la bile jaune et le flegme) au principe de la classification des tempéraments humains et de la médecine. Cet ouvrage prend ainsi place dans le sillage des recherches précédentes de l'auteur, professeur de littérature française en Sorbonne: les deux tomes de Molière et la maladie imaginaire, ou encore Sganarelle et la médecine ou de la mélancolie érotique (parus chez le même éditeur en 1993 et 1998). Mais, ici, le propos s'élargit et s'antériorise: il dépasse l'examen des liens qui unissent le théâtre de Molière à la médecine, pour consacrer un chapitre (le troisième) à la généalogie de l'imaginaire de la mélancolie - donc aux textes antiques ${ }^{1}-$, et surtout pour considérer les formes dramatiques de la mélancolie à l'époque baroque.

Il s'agit bien d'une « période privilégiée », qui voit s'imposer une véritable mode de la mélancolie dans les sciences, les lettres et les arts. Pour autant, le livre s'attache en grande partie à montrer que le modèle mélancolique vit entre 1580 et 1680 un «apogée au bord d'un abîme». L'édifice scolastique de la physiologie et de l'anatomie se trouve en effet attaqué de tous les côtés. Or, c'est à l'intérieur de cet édifice que le principe mélancolique offrait un modèle très puissant d'explication de tout un corpus de maladies aujourd'hui qualifiées de «mentales»,

\footnotetext{
* Paris, Klincksieck, coll. «Le génie de la mélancolie», 2003.

1. Ces textes sont: l'aphorisme VI, 23 d'Hippocrate, les traités de Galien, le Problème XXX du pseudo-Aristote ou encore les Lettres hippocratiques.
} 
en s'appuyant sur les principes de la médecine humorale et une compréhension encore physiologique des rapports de l'âme et du corps. Le modèle ne résiste donc pas devant les avancées rationalistes et la compréhension mécaniste du corps, ni devant les premiers pas de la psychologie.

La méthode d'investigation retenue par le livre consiste à «se placer au point de rencontre entre ces deux systèmes de représentation de la mélancolie que constituèrent, durant l'époque baroque [...], la doctrine éthico-médicale du désordre atrabilaire et la dramaturgie de la folie, de l'égarement et de la prostration tragiques ou comiques ». C'est principalement à cette dramaturgie, qui connaît un immense succès de l'Espagne à l'Angleterre en passant par la France, que l'auteur consacre ses analyses.

Pour le lecteur, l'entreprise présente des enjeux particulièrement stimulants : il s'agit, et Patrick Dandrey le fait souvent au détour d'une phrase, presque discrètement, de ressourcer la théorie littéraire aux apports de l'histoire, littéraire ou des idées. C'est ce qui se passe par exemple aux chapitres V et VI (respectivement: «La cure du délire. D'un théâtre d'ombres » et «Catharsis et mélancolie. La rédemption par les Lettres»). Avec les lunettes de la mélancolie, l'auteur relit la Poétique et montre qu'un même mouvement régit la cure du fou, l'effet du spectacle dramatique et l'écriture du génie: dans tous les cas, bien que selon des modalités différentes, il est question d'excès de bile, de purgation - préventive ou nécessaire - et de mise à distance du mal ou des visions par la représentation. L'analyse qui mène à ces conclusions donne lieu au passage à un inventaire fort divertissant de saynètes ou d'anecdotes de guérison de diverses folies, et cet inventaire conduit l'auteur à nuancer la «faille épistémologique» proposée par Michel Foucault dans son Histoire de la folie à l'âge classique.

En outre, cette position à mi-chemin entre histoire des idées et histoire littéraire permet de lire le théâtre du XVII ${ }^{e}$ siècle à la lumière de son contexte anthropologique, médical et moral. Les deux premiers chapitres ( «Le sang de Don Gormas et les yeux de Junie. L'imaginaire juridique, médical et érotique de la contamination oculaire» et «Les humeurs de Lucinde. Du mal d'amour à la mélancolie érotique»), qui s'intéressent à Corneille, Racine et Molière, sont les meilleurs témoignages de la fécondité d'une telle position. Sans s'arrêter au constat d'une identité de l'imaginaire de l'œuvre avec celui du temps, les liens 


\section{Les Tréteaux de Saturne}

que l'interprétation - extrêmement convaincante - noue entre médecine et théâtre permettent de rendre compte du détail du texte dramatique, d'en expliquer la forme et d'en reconstituer les effets. Et le récit de Néron s'éclaire d'un jour nouveau, celui de cet ancien imaginaire retrouvé par une lecture érudite des traités de morale ou de médecine. L'analyse du regard dans Britannicus, de son pouvoir et de ses effets, et des formes littéraires qu'ils prennent, permet au lecteur de comprendre le ravissement racinien: «Si la rhétorique de l'ecphrase et la topique galante condensée dans la pointe ont pu être enrôlées par Racine au service d'une peinture inédite de la passion amoureuse, c'est probablement à l'imaginaire médico-moral de la contamination oculaire qu'il le doit » (p. 49).

Le chapitre III est le moment de la découverte du débat qui était déjà présent aux sources du système, entre deux conceptions de la mélancolie: l'une ontologique, incluant le corps et l'esprit, et l'autre analogique, la maladie du corps devenant l'image des souffrances de l'âme.

Après ce détour nécessaire, le lecteur retrouve le théâtre baroque avec La Folie du sage de Tristan l'Hermite qui met en scène ce débat et les ambiguïtés de la mélancolie, «aiguillon de l'esprit ou désastre de l'âme, instrument de sagesse ou cause de folie». La fin de l'ouvrage prolonge des idées esquissées jusque-là au fil du texte en écrivant une naissance de la psychologie à travers la sorcellerie (démoniaque ou hystérique) et la maladie imaginaire chez Molière (qui «a su dessiner une aliénation obsessionnelle que son époque ne savait pas désigner»).

Ces derniers avatars de la mélancolie ponctuent la fin de la bile noire comme «mythe majeur de l'imaginaire médical, moral, anthropologique, esthétique». Si le style, très travaillé et souvent élégant, s'obscurcit parfois, demandant alors au lecteur une attention de tous les instants pour saisir les distinctions subtiles mises en place, et si les textes dramatiques restent dans certains chapitres au second plan, le lecteur devient au fil des analyses spectateur étonné et passionné de ces «noces de Théâtre et Mélancolie».

En jouant le rôle de passeur entre le corps et l'âme, la bile noire a ouvert le continent des maladies de l'âme et des délires fantasmatiques : «par ce double rôle, [elle] pactise avec une autre invention spécifique de l'imaginaire occidental : la pratique du théâtre conçu comme spec- 
tacle de l'homme réincarné en un autre lui-même, au sein d'une fiction narrative crédible qui jouxte, qui double la réalité. Le rôle de passeur dévolu à l'atrabile entre l'âme et le corps, son rôle de révélateur spectrographique des secrets de la psyché à travers le spectacle patent de la physis, consonait avec le mystère dramatique de la révélation d'une âme par le truchement d'un corps mis en scène» (p. 293). 